\title{
Design of solar systems in high-rise buildings
}

\author{
Alexander Kolosov ${ }^{1 *}$, Dmitry Chudinov ${ }^{1}$, Sergey Yaremenko ${ }^{1}$ \\ ${ }^{1}$ Voronezh State Technical University, Moscow Avenue, 14, Voronezh, 394026, Russia
}

\begin{abstract}
Nowadays, the renovation program is being implemented in the megapolises of Russia. Innovative high-rise buildings are built instead of morally and physically obsolete houses, where non-traditional renewable energy sources are used to the fullest extent, under the effect of which they are located. The possibility to use solar systems with variation of their design parameters is considered. It is established that solar systems have high technical potential. The share of heat load, that is provided by using solar energy, varies from 4 to $84 \%$ depending on the time of the year. Economic indicators restrain the use of such panels. The payback period is about 8 years at the current cost for thermal energy.
\end{abstract}

\section{Introduction}

Currently in Russia, comfortable high-rise buildings are being erected within the renovation program in order to substitute morally and physically obsolete dwellings. Apartments on the last floors are often two-level. The area of apartments is 200 to $300 \mathrm{~m}^{2}$, which is comparable with the area of a cottage. It is possible to use alternative resources for energy supply in order to increase energy efficiency, reduce the operating costs of similar apartments and buildings in general.

The use of solar energy to heat water can be practically significant and promising. Solar power plants have a number of advantages: saving fuel and energy resources; low operating costs; simplicity of design and reliability in work; minimal maintenance; durability; complete safety. The profitability of the use of such systems for different regions of the country is determined by the gross, technical and economic potential of solar energy [1-4].

The gross potential of solar radiation is determined by its intensity, which depends on many factors: latitude, longitude, air conditions, hydrometeorological conditions of the region, time of year and day. The existing formulas for determining solar radiation do not always give an accurate estimate [5]. The authors suggest using the data of long-term actual observations when calculating the gross potential of solar radiation.

The data on solar radiation, presented in the reference books in the form of tables, should be used in the form of correlations, determined on the basis of the approximation of these tabular data in order to intensify large-scale thermal engineering calculations.

Analytical dependencies that allow determining the values of the total solar radiation on a horizontal and vertical surface amid a cloudless sky for the corresponding latitude were obtained.

\footnotetext{
* Corresponding author: kolossn@yandex.ru
} 


$$
\begin{gathered}
H_{j a n}=-614.08 \cdot \ln (\varphi)+2586.09 \\
\ldots \\
H_{\text {jume }}=0.00005571 \cdot \varphi^{5}-0.01486526 \cdot \varphi^{4}+1.57018502 \cdot \varphi^{3}-82.03553868 \cdot \varphi^{2}+ \\
+2117.99506113 \cdot \varphi-20707.95629264 \\
\ldots \\
H_{\text {dec. }}=-623.75 \cdot \ln (\varphi)+2596.38
\end{gathered}
$$

In order to take into account the cloud cover, the values obtained from these correlations must be multiplied by the corresponding correction factor $(\psi)$, which is the ratio of the value of the total solar radiation under the actual cloudiness conditions $\left(I_{\Sigma}^{O}\right)$ to the total solar radiation amid a cloudless sky $\left(I_{\Sigma}^{Y}\right)$.

$$
\psi=\frac{I_{\Sigma}^{O}}{I_{\Sigma}^{Y}} .
$$

The replacement factor (the share of the heat load provided by solar energy) is applied to determine the technical potential of solar energy in heat supply and hot water supply systems.

The estimate of the dependence of the replacement factor on the variation in the design parameters of the solar heat supply and hot water supply systems is given in the article. The estimate of economic potential at a variation of cost for thermal energy is also given.

\section{Materials and Methods}

Among the various possible aspects of the use of solar energy, the most technically and economically prepared field is the utilization of solar energy for the heat supply of housingand-utility and agricultural facilities. The obtained in this case ecological effect is determined by the consumption of the replaced organic fuel and is directly dependent on the efficiency of solar heat supply systems.

Solar heating systems operate on a technically simple principle. The core element of the solar heating system, where solar radiation is converted into thermal energy, is the solar collector. A solar thermal collector collects heat by absorbing sunlight. A collector is a device for capturing solar radiation. Solar radiation is energy in the form of electromagnetic radiation from the infrared (long) to the ultraviolet (short) wavelengths.

The term "solar collector" commonly refers to solar hot water panels, but may refer to installations such as solar parabolic troughs and solar towers; or basic installations such as solar air heaters. Solar collectors can be used both with concentration and without concentration of solar radiation. A surface in flat collectors that receives solar radiation is also a surface that absorbs radiation. Focusing collectors, which usually have concave reflectors, concentrate radiation incident on their entire surface onto a heat exchanger with a smaller surface area, thereby increasing the energy flux density. The advantages of flat collectors include the possibility to use both direct and scattered solar radiation, they do not require tracking the sun and daily maintenance. In a constructional way, they are simpler than a system with concentrating reflectors, absorbing surfaces and tracking mechanisms. At the present moment, flat collectors are used in solar heating systems.

The solar energy, that is converted by the solar collector into heat, is accumulated in the storage tank due to the heat capacity of the liquid and is used when necessary to provide the heat load of the heating and hot water supply. Water is used as the heat carrier in the heating system and hot water supply system and antifreeze is used in the solar circuit to 
prevent freezing during the cold period of the year. A conventional boiler is used as a backup source of energy, which provides heating in those cases when the storage bank is empty. The set of solar heating system equipment includes regulators, safety valves, pumps and pipelines.

\section{Results}

The following values of the replacement factors were obtained in [5]: 21.2 to $33.7 \%(19.5$ to 34.7 are experimental values) with a variation in the area of the solar collector from 5 to $20 \mathrm{~m}^{2} ; 23.9$ to $31.6 \%$ (22.4 to 34.2 are experimental values) with a variation in the tank volume of the battery from 0.25 to $1 \mathrm{~m}^{3}$ (Figure 1,2).

The values of the replacement factor grow with the increase of the area of the solar collector, however, an increase of the solar collector area over $15 \mathrm{~m}^{2}$ does not contribute to a significant increase in it. The optimal tank volume of the battery is in the range from 0.75 to $1 \mathrm{~m}^{3}$.

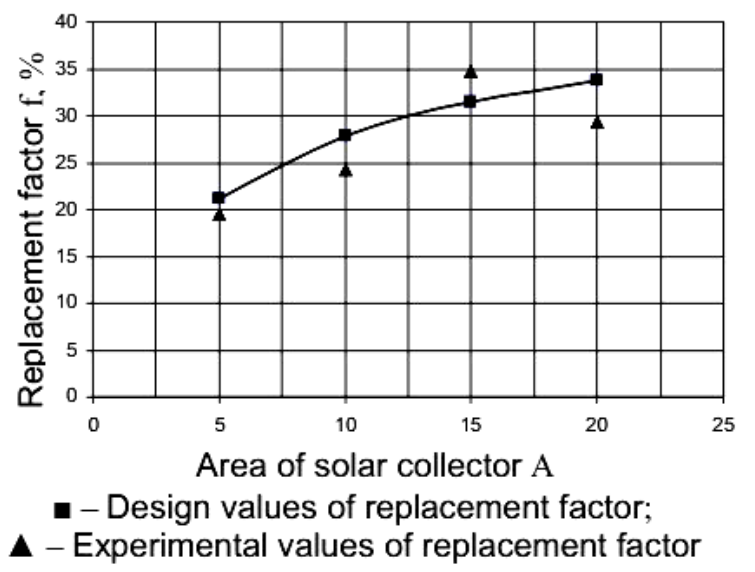

Fig. 1. Dependence of the replacement factor on the area of the solar collector (the tank volume of the battery is $0.75 \mathrm{~m}^{3}$ ).

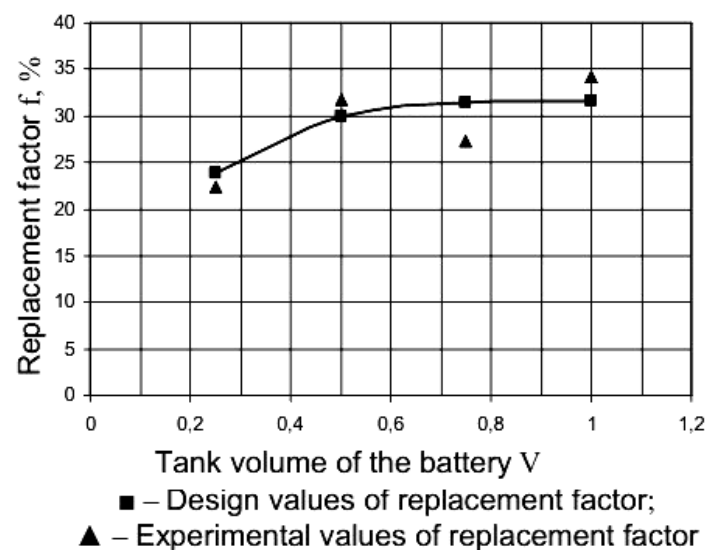

Fig. 2. Dependence of the replacement factor on the tank volume of the battery (solar collector area is $\left.15 \mathrm{~m}^{2}\right)$. 


\section{Discussions}

The evaluation of the efficiency of investments in solar energy systems can be defined in accordance with the Recommendations on the Assessment of the Economic Efficiency of the Heat Supply Investment Project developed by the NP "ABOK" . There were identified the following criteria: a) additional discounted expenses (DE) for solar heating and hot water supply systems over the accounting period; b) the payback period (Flow) of additional expenses for solar heating hot water supply systems.

A residential house (cottage) was considered as an object to evaluate its economic efficiency, which can be compared with multi-level apartments in high-rise buildings. The need for thermal energy is carried out either by the traditional system of power supply (I option), or by a combination of solar and traditional systems (II option). The system is equipped with solar collectors with a total area of $12 \mathrm{~m}^{2}$, the tank volume of the heatinsulated battery is 600 liters. There is antifreeze in the solar collector circuit. The battery tank has a built-in heat exchanger. The system is equipped with a device for coolant circulation and automation. The replacement factor of thermal load was defined for the calendar year as a whole according to the method presented in [6].

The additional discounted expenses (DE) for the compared options are defined from the expressions [7]:

$$
\begin{aligned}
& D E_{I}=\left(K_{I}+\sum_{t=1}^{T s l} \frac{E_{I t}-E_{\text {Iat }}}{(1+r)^{t}}\right), \\
& D E_{I I}=\left(K_{I I}+\sum_{t=1}^{T_{s l}} \frac{E_{I I t}-E_{\text {Ilat }}}{(1+r)^{t}}\right),
\end{aligned}
$$

where (according to the options): $\mathrm{K}$ - capital investment; $\mathrm{E}_{\mathrm{t}}, \mathrm{E}_{\mathrm{at}}$ - operating expenses and depreciation charges per year $\mathrm{t} ; \mathrm{r}$ - interest rate (discount rate), rel. units [ ]; $\mathrm{T}_{\mathrm{sl}}$ - time horizon (acounting period).

The obtained on the basis of a number of performed calculations results are illustrated in Figures 3 and 4.

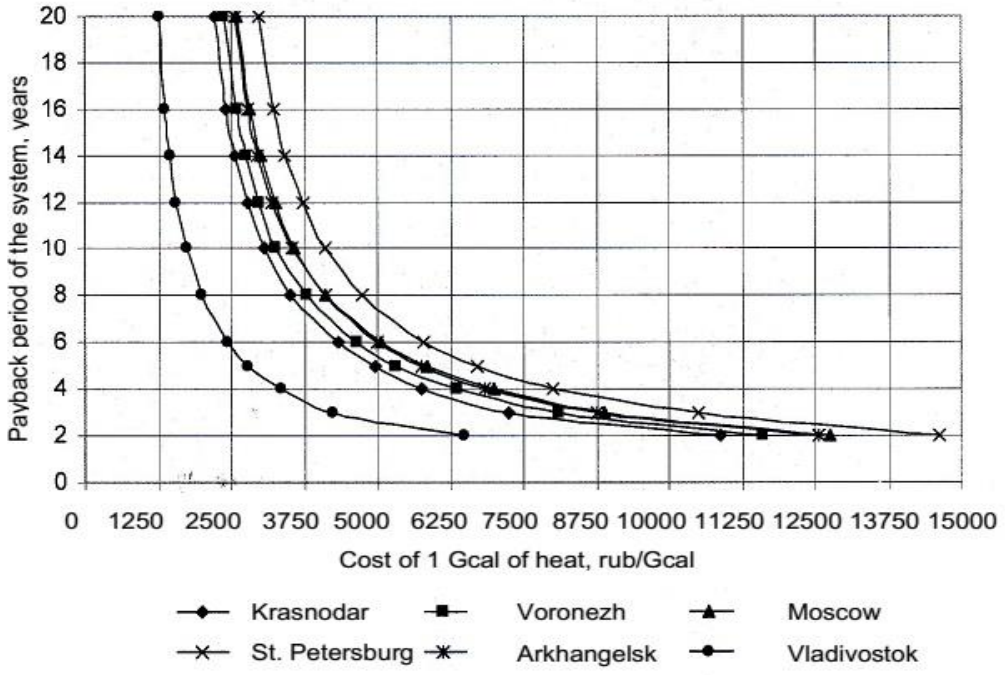

Fig. 3. Dependence of the payback period of the solar energy system on the cost of heat. 

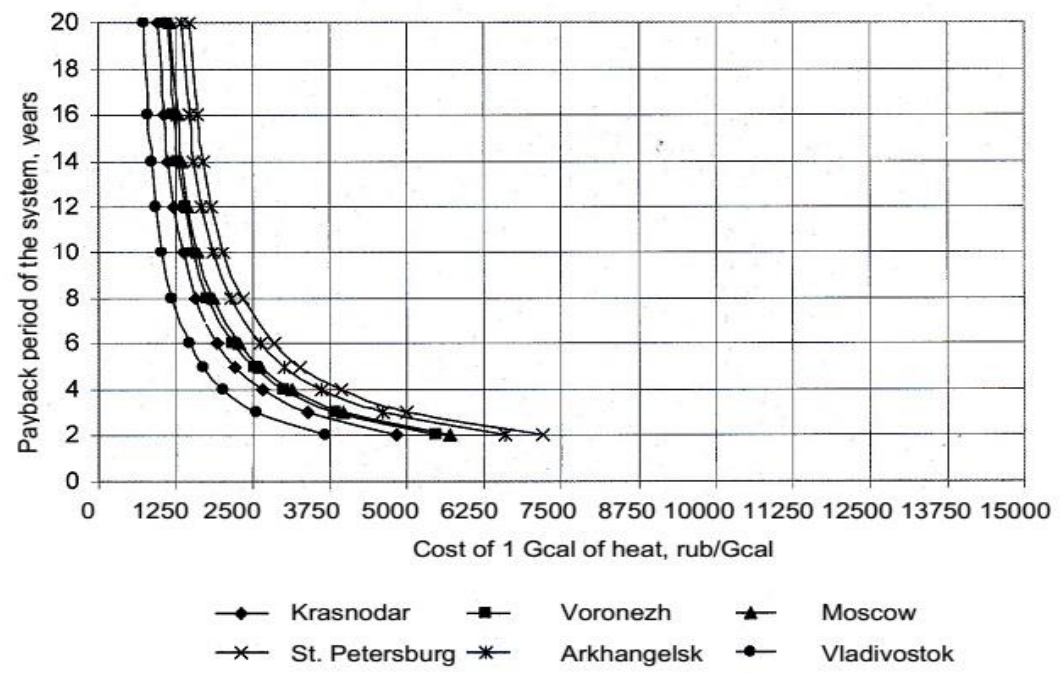

Fig. 4. Dependence of the payback period of the solar hot water supply system on the cost of heat.

\section{Conclusion}

The scale of solar systems use in Russia is determined by a number of factors: climatic conditions, economic reasons and technical capabilities.

It is possible to increase the energy efficiency of buildings and reduce operating expenses through using solar systems for the needs of heat supply and hot water supply within the renovation program. Solar power plants are among of the most satisfactory technologies of heat supply.

Mutual efforts of researchers, developers, manufacturers and the state are required in order to successfully introduce solar systems for partial energy supply of high-rise buildings. It is necessary to increase their competitiveness by applying improved technical solutions (combined generation of thermal and electric energy) and reducing cost parameters.

The payback period of solar systems (according to the assumed initial data), depending on the region where they are applied, varies from 3 years (hot water supply systems) to unprofitable value (heat supply systems).

It is apparent that an increase in the cost of heat will lead to a reduction in the payback period of solar plants.

\section{References}

1. E. Nezhnikova, IOP Conf. Series: Earth and Environmental Science, 90 (2017) DOI:10.1088/1755-1315/90/1/012161

2. V. Kankhva, IOP Conf. Series: Earth and Environmental Science, 90 (2017) DOI:10.1088/1755-1315/90/1/012175

3. O. Sotnikova, Vestnik Voronezhskogo gosudarstvennogo tekhnicheskogo universiteta, 6, 56-63 (2005)

4. D. Chudinov, T. Shchukina, O. Sotnikova, Promyshlennaya ehnergetika, 9, 44-46 (2008)

5. D. Chudinov, Energosberezhenie, 7, 64-80 (2009) 
6. A. Borboni, D. De Santis, Meccanica, 49, 1327-1336 (2014) DOI: 10.1007/s11012-0149895-z

7. A. Borboni, F. Aggogeri, R. Faglia, International Journal of Advanced Robotic Systems, 10, 149 (2013) DOI: 10.5772/55539 